\title{
CLINIQUIZ
}

\section{Anesthesia in hepatobiliary disorders}

\author{
Priyanka Sehrawat $^{1}$, Ankur Karn ${ }^{1}$, Pranav Bansal ${ }^{2}$ \\ 1- Resident; 2- Professor \& HoD; Department of Anesthesiology \& Critical Care, BPS Govt Medical College, Khanpur Kalan, \\ Sonepat, Haryana, India.
}

Correspondence: Prof. Pranav Bansal, Department of Anesthesiology \& Critical Care, BPS Govt Medical College, Khanpur Kalan, Sonepat, Haryana, India; E-mail: pranavbansal1@gmail.com; Phone: +91 822200555

Multiple factors have led to an increased incidence of hepatobiliary disease across the continents, and with it we witness an increased number of patients, who report for surgery for a hepatobiliary disease, e.g. hepatic lobectomy, cholecystectomy, corrective surgery on bile ducts and even liver transplantation, or they report for surgery for an unrelated disease but with a concurrent hepatobiliary disease. These patients require special considerations during perioperative period. Please select the one best option in each of the following questions.

Q 1. Which of the following is an incorrect match regarding the grade of Hepatic Encephalopathy:-
A. Grade 1- Slurred speech
B. Grade 2- Drowsy but easily arousable
C. Grade 3- Sleepy and unresponsive to pain
D. Grade 4- Unresponsive to voice

Q 2. Which of the following is an absolute contraindication to Liver Transplantation?
A. Portal vein thrombosis
B. AIDS
C. Age $>70$ yrs
D. Severe Obesity

Q 3. Mark the incorrect statement for patient selected for Liver Transplantation according to MILAN Criteria:-
A. One lesion smaller than $5 \mathrm{~cm}$
B. Upto 3 lesions smaller than $3 \mathrm{~cm}$
C. Upto 5 lesions smaller than $1 \mathrm{~cm}$
D. No extra-hepatic manifestation

Q 4. Which of the following is a feature of hepatorenal syndrome?
A. High $\mathrm{Na}^{+}$in urine
B. Normal GFR
C. Type 2 Hypersensitivity reaction has poor prognosis as compared to Type 1 hypersensitivity reaction
D. Normal urinary sediments

Q 5. Incorrect statement about Liver Transplantation is:-
A. Done if MELD score $>17$
B. Recurrence with Wilsons Disease
C. HLA matching is not mandatory
D. University of Wisconsin solution for prolongation of cold ischemia time

Q 6. Which of the following is correct statement regarding Child Pugh Score:-
A. Parameters include s. bilirubin, s. albumin and s. creatinine
B. Values range from 5 to 15
C. Grade A is decompensated disease
D. Score of 8 is not an indication for orthoptic liver transplantation

Q7. Which of the following is the most common cause of pre-sinusoidal intrahepatic portal hypertension:-
A. Cirrhosis
B. Graft vs host disease
C. Sarcoidosis
D. Schistosomiasis

Q 8. A 60-year-old female, known case of chronic liver disease (CLD) with splenomegaly. She presented with platypnea-orthodeoxia syndrome, malena, cyanosis, clubbing and blood stained vomitus. Her arterial blood gas analysis reveals hypoxemia. What is the probable diagnosis?
A. Hepatopulmonary syndrome
B. Hepatorenal syndrome
C. Non-alcoholic fatty liver disease
D. Cirrhosis

Q 9. Mark the correct statement regarding shock liver (ischemic hepatitis):-
A. Inflammation of hepatic cells
B. Most common cause is hepatitis A
C. Increased serum aminotransferases
D. Always leads to liver failure

Q 10. All are abnormal in alcoholic CLD, except:
A. AST:ALT ratio $>2: 1$
B. ALP normal or increased
C. Albumin normal or increased
D. SGOT/SGPT ratio 8 times of normal 


\section{Explanations:}

Ans 1: (C)

Grade 1: Poor concentration, slurred speech, slow thinking, and abnormal sleep rhythm

Grade 2: Drowsy but easily arousable, occasional aggressive behavior, lethargic

Grade 3: Confusion, drowsy, sleepy but responds to pain and voice

Grade 4: Unresponsive to voice, unconscious, may or may not respond to painful stimuli

Ans 2: (B)

\begin{tabular}{|l|l|}
\multicolumn{1}{|c|}{$\begin{array}{c}\text { Absolute } \\
\text { Contraindication }\end{array}$} & \multicolumn{1}{c|}{$\begin{array}{c}\text { Relative } \\
\text { Contraindication }\end{array}$} \\
\hline $\begin{array}{l}\text { Uncontrolled } \\
\text { hepatobiliary infection }\end{array}$ & Age > 70 years \\
\hline Sepsis & Portal vein thrombosis \\
\hline AIDS & Severe Obesity \\
\hline Cholangiocarcinoma & $\begin{array}{l}\text { HIV seropositive with low } \\
\text { CD4 counts }\end{array}$ \\
\hline Metastasis to liver & $\begin{array}{l}\text { PAH (pulmonary artery } \\
\text { hypertension) }\end{array}$ \\
\hline $\begin{array}{l}\text { Advanced } \\
\text { cardiopulmonary disease }\end{array}$ & Psychiatric disorders \\
\hline $\begin{array}{l}\text { Active substance/ } \\
\text { alcohol abuse }\end{array}$ & \\
\hline
\end{tabular}

Ans 3: (C) Milan criteria are applied as a basis for selecting patients with cirrhosis and hepatocellular carcinoma for liver transplantation. The Milan criteria states that a patient is selected for transplantation when he or she has:

- One lesion smaller than $5 \mathrm{~cm}$.

- 2-3 lesions smaller than $3 \mathrm{~cm}$.

- No extrahepatic manifestations.

- No vascular invasion.

Ans 4: (D) Hepato-renal syndrome (HRS) is a form of functional renal failure without renal pathology. The GFR decreases; however, urinary sediments and renal biopsy stays normal. Diagnosis is made in the presence of large amount of ascites in patients who have a stepwise progressive increase in creatinine.
- Type 1 HRS is characterized by a progressive impairment in renal function and a significant reduction in creatinine clearance within 1-2 weeks of presentation.

- Type 2 HRS is characterized by a reduction in GFR with an elevation of serum creatinine level, but it is fairly stable and is associated with a better outcome than that of Type 1 HRS.

Ans 5: (B)

- Following perfusion with cold electrolyte solution, the donor liver is removed and packed in ice. The use of University of Wisconsin (UW) solution, rich in lactobionate and raffinose, has permitted the extension of cold ischemic time upto $20 \mathrm{~h}$. Recurrence after Wilson and alpha 1 antitrypsin deficiency is not seen and tissue typing for HLA matching is not mandatory.

- MELD score (Model For End Stage Liver Disease) consists of serum creatinine, bilirubin, INR and serum sodium with a minimum score of 6 and maximum score of 40. Liver transplantation done if MELD score $>17$

Ans 6: (B) Parameters in Child-Pugh score include s. bilirubin, s. albumin, PT/INR, ascites and hepatic encephalopathy. Child Pugh score is calculated by adding the scores of the five factors and can range from 5 to 15. Presence of cirrhosis with a Child Pugh score of $>7$ indicates decompensation. This level has been the accepted criterion for listing liver transplantation.

\begin{tabular}{|l|c|c|}
\hline \multicolumn{1}{|c|}{ Grade } & Points & $\begin{array}{c}\text { One Year Patient } \\
\text { Survival (\%) }\end{array}$ \\
\hline $\begin{array}{l}\text { A. Well compensated } \\
\text { disease }\end{array}$ & $5-6$ & 100 \\
\hline $\begin{array}{l}\text { B. Significant function } \\
\text { compromise }\end{array}$ & $7-9$ & 80 \\
\hline $\begin{array}{l}\text { C. Decompensated } \\
\text { disease }\end{array}$ & $10-15$ & 45 \\
\hline
\end{tabular}

Ans 7: (D)

Ans 8: (A) 
- Spontaneous bacterial peritonitis (SBP) is a severe complication of ascites characterized by spontaneous infection of the ascitic fluid without an intra-abdominal source. Most common organism is E. Coli. Absolute neutrophil count $>250 / \mathrm{ml}$ and ascitic tap having neutrophil count $>250 / \mathrm{mcgl}$ is diagnostic.

- Peritoneal fluid is transudate in cirrhosis with protein levels $<2.5 \mathrm{gm} / \mathrm{dl}$.

- Patients with ascites may present with fever, altered mental status, abdominal pain or discomfort and elevated WBC count.
- Bacterial Translocation - gut flora traversing the intestine into mesenteric lymph nodes, leading to bacteremia and seeding of the ascitic fluid.

Ans 9: (C) Shock liver also $\mathrm{k} / \mathrm{a}$ ischemic hepatitis is a condition characterised by acute liver injury due to insufficient blood flow (insufficient oxygen delivery) to liver. The decreased perfusion to liver is usually due to shock or low blood pressure. Inflammation of liver cells is absent. Blood tests shows high levels of serum aminotransferases which may exceed 10,000 U/L.

Ans 10: (C) 